Check for updates

Cite this: Phys. Chem. Chem. Phys., $2018,20,8737$

Received 13th November 2017 Accepted 20th February 2018

DOI: $10.1039 / c 7 c p 07642 h$

rsc.li/pccp

\section{Real time evolution of unprotected protonated galactosamine probed by IRMPD spectroscopy $\dagger$}

\author{
C. Fraschetti, (D)*a L. Guarcini, (D) ${ }^{a}$ C. Zazza, (D) ${ }^{b}$ L. Mannina, (D) ${ }^{a}$ S. Circi, (D) ${ }^{a}$ \\ S. Piccirillo, (D) ${ }^{c}$ B. Chiavarino (D) and A. Filippi (D) ${ }^{a}$
}

\begin{abstract}
Conformational characterization of single $\alpha$ - and $\beta$-epimers of galactosamine in solution still remains an intriguing task because of their flexibility and ability to interconvert. This difficulty was circumvented by recording several "snapshots" of the epimerization process by means of fast ESI vaporization of a galactosamine. $\mathrm{HCl}$ sample solution at different times. Consequently, the so generated gaseous mixtures were spectroscopically investigated and the specific conformational features of both $\alpha$ - and $\beta$-epimers were assigned, despite the overlapping of several IR signals. Interestingly, from a comparison with timeresolved ${ }^{1} \mathrm{H}$-NMR data obtained for the same solutions, the catalyzing effect of the applied ESI technique in the anomerization process clearly emerges. Finally, the experimental data were supported using both the Density Functional Theory (DFT) and Block-Localized Wavefunction (BLW) approaches: the latter method was applied here for the first time for the investigation of charged species.
\end{abstract}

\section{Introduction}

2-Aminosugars are monosaccharide derivatives present in a modified form in several biopolymers, as for instance chitin (a functional component of cell walls in many living organisms, as well as of the exoskeleton of insects, crustaceans, etc.), glycoprotein hormones involved in the human reproductive process (FSH, LH), galactosaminoglycan, ${ }^{1}$ and arabinogalactan. ${ }^{2}$ From a fundamental standpoint, their importance lies in the simple but unique structure that can assume an archetypal behavior. Indeed, 2-aminosugars can experience different conformations as a consequence of several factors, including the electronic delocalization and the electrostatic terms, as well as the peculiar hydrogen bonding network available for the hydroxyl substituents and the amino group. A number of computational ${ }^{3}$ and experimental efforts have been devoted to the conformational study of sugars and their modified oligomers in the gas phase, ${ }^{4}$ as for instance using FT-microwave spectroscopy, ${ }^{5-7}$ electronic and vibrational spectroscopy in molecular beams, ${ }^{8}$ but a significant lack of data concerns the conformational characterization of 2 -aminosugars. ${ }^{9}$ The present paper proposes mass spectrometry (MS) as an experimental approach for the

\footnotetext{
${ }^{a}$ Dipartimento di Chimica e Tecnologie del Farmaco, Sapienza-Università di Roma, P.le Aldo Moro 5, 00185, Rome, Italy. E-mail: caterina.fraschetti@uniroma1.it

${ }^{b}$ Dipartimento di Chimica, Sapienza-Università di Roma, P.le Aldo Moro 5, 00185 , Rome, Italy

${ }^{c}$ Dipartimento di Scienze e Tecnologie Chimiche, Università di Tor Vergata, via della Ricerca Scientifica, 00133, Rome, Italy

$\dagger$ Electronic supplementary information (ESI) available. See DOI: 10.1039/ $\mathrm{c} 7 \mathrm{cp} 07642 \mathrm{~h}$
}

structural investigation of charged 2-aminosugars. Well known intrinsic limitations of MS techniques in terms of structural resolving power have been overcome through a MS/IR spectroscopy coupling achieved by interfacing a gas-phase ion storing device (e.g. a Paul ion trap or an FT-ICR mass spectrometer) with a tunable IR laser beam. In the last few years the infrared multiphoton dissociation (IRMPD) technique has been extensively employed to assess the conformations that biological molecules assume in the gas phase. ${ }^{10-17}$ In the present work the ESI-IRMPD-MS spectrum of protonated galactosamine (GalN. $\mathbf{H}^{+}$) has been measured to determine for the first time the features of unprotected $\alpha$-GalN $\cdot \mathbf{H}^{+}$and $\beta$-GalN $\cdot \mathbf{H}^{+}$anomers. Their conformational landscape includes four main degrees of freedom: (1) the position of the ${ }^{1} \mathrm{C}_{4} \rightleftharpoons{ }^{4} \mathrm{C}_{1}$ chair equilibria (Fig. 1); (2) the O5-C5-C6-O6 and (3) C5-C6-O6-H6 dihedral angles (symbolized through capital and small letters, respectively, in Fig. S1 in the ESI $\dagger$ ), and finally (4) the clockwise (cl) or counterclockwise (cc) orientation of the $\mathrm{O} 3 \mathrm{H}-\mathrm{O} 4 \mathrm{H}-\mathrm{O} 6 \mathrm{H}$ hydrogen bond network. The experimental spectra have been interpreted with the support of B3LYP/6-311++G(d,p) calculations in order to assess the vibrational contributions of both $\alpha$-GalN $\cdot \mathbf{H}^{+}$and $\beta$-GalN. $\mathbf{H}^{+}$ anomers and their conformational features. A further issue we faced concerns the investigation of the electrospray ionization (ESI) effect on the epimerization. In other words, does the ESI-IRMPD-MS result reflect the anomeric distribution in the analyzed solutions or it is affected by the local physicochemical properties of the dynamic ESI environment? In order to answer this question, we compared the anomeric distribution arising from the ESI-IRMPD-MS experiment with that recorded in the condensed phase using ${ }^{1} \mathrm{H}-\mathrm{NMR}$ measurements. 


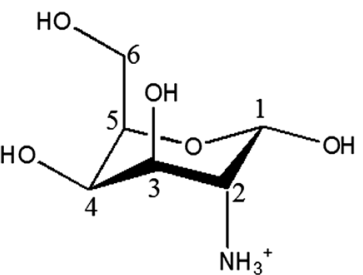

$$
\alpha-{ }^{1} \mathrm{C}_{4} \mathbf{G a l N} \cdot \mathrm{H}^{+}
$$

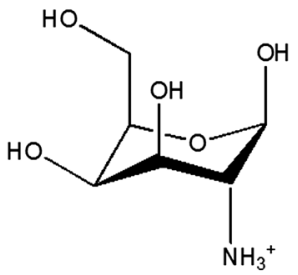

$\beta-{ }^{-1} \mathrm{C}_{4} \mathbf{G a l N} \cdot \mathrm{H}^{+}$

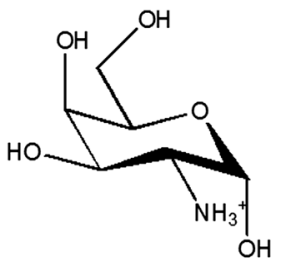

$\alpha-{ }^{4} \mathrm{C}_{1}$ GalN $\cdot \mathrm{H}^{+}$

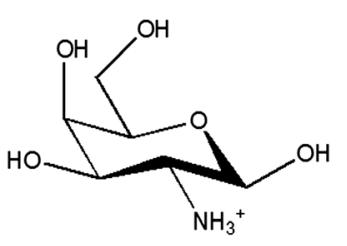

$\beta-{ }^{4} \mathrm{C}_{1} \mathbf{G a l N} \cdot \mathrm{H}^{+}$

Fig. $1{ }^{1} C_{4}$ and ${ }^{4} C_{1}$ chairs of protonated $\alpha$ - and $\beta$-D-galactosamine.

Since the anomerization of sugars and their derivatives was discovered, a lively theoretical debate has grown about the nature and role of the factors regulating the relative stability of anomeric species. Nevertheless, the diatribe centered on the classic dichotomy between the electronic delocalization and the electrostatic models, typically claimed to explain the conformational preference of the substituent adjacent to a heteroatom in six membered ring, still stimulates interest, since more than 500 papers have been published on the topic only in the last 10 years. In particular, the debate ${ }^{18-22}$ has recently revived because of Mo's paper, ${ }^{18}$ which indicates the electrostatic contribution as the main factor driving the anomeric effect. However, the MO's theoretical approach (the so-called BlockLocalized Wavefunction method - BLW, which is based on the Valence bond theory) was exclusively applied to neutral species. In this contribution, driven by the curiosity of investigating the chemical factors regulating the anomeric distribution of $\alpha$ - and $\beta$-GalN $\cdot \mathbf{H}^{+}$epimers in the gas-phase and inspired by the literature previously cited, we report on the first application of the BLW method to protonated species, i.e. $\alpha$ and $\beta$ epimers of GalN $\cdot \mathbf{H}^{+}$.

\section{Experimental}

\subsection{IRMPD experiments}

D-Galactosamine-HCl (Sigma-Aldrich) was purchased as a mixture of anomers and then dissolved to a final concentration of $10^{-5} \mathrm{M}$ methanol solution without further purification. From the ESI source, the GalN $\cdot \mathbf{H}^{+}$ions $(\mathrm{m} / \mathrm{z} 180 \mathrm{u})$ were introduced in a modified Bruker Esquire 6000 quadrupole ion trap, and isolated using the standard Bruker Esquire Control (v6.2) software. ESI conditions used were as follows: a syringe pump rate of $180 \mathrm{~mL} \mathrm{~h}^{-1}$; a spray voltage of $3500 \mathrm{~V}$; a capillary temperature of $250{ }^{\circ} \mathrm{C}$. Mass-selected ions were irradiated using the MS2 step, in which the excitation amplitude was set to zero to avoid any collision-induced dissociation (CID) process. Mass spectra were recorded in the standard mass range $(\mathrm{m} / \mathrm{z} 50-3000 \mathrm{u})$ and

normal scan-mode resolution (13000 $\left.\mathrm{u} \mathrm{s}^{-1}\right)$, with the accumulation time fixed at $1 \mathrm{~s}$. The $2800-3700 \mathrm{~cm}^{-1}$ wavenumber range was explored using an IR OPO/OPA system of LaserVision, pumped by a $10 \mathrm{~Hz} \mathrm{Nd:YAG} \mathrm{laser} \mathrm{(Excel} \mathrm{Technology} \mathrm{Europe} \mathrm{GmbH} \mathrm{Surelite-II,}$ $650 \mathrm{~mJ}$ per pulse, $8 \mathrm{~ns}$ pulse duration). The output energy, measured between 3400 and $3600 \mathrm{~cm}^{-1}$, is about $22 \mathrm{~mJ}$ per pulse with a spectral bandwidth of approximately $5 \mathrm{~cm}^{-1}$. The loss of energy in the other investigated spectral regions is no more than $14 \%$. The photon energy was increased at a rate of $0.1 \mathrm{~cm}^{-1} \mathrm{~s}^{-1}$. The only charged fragment resulting from either CID or IRMPD of isolated GalN $\cdot \mathbf{H}^{+}$ions is its corresponding dehydrated derivative $(\mathrm{m} / \mathrm{z} 162 \mathrm{u})$. The reported spectra represent the wavelength dependence of the fragmentation efficiency, defined as $R=-\log \left[\left(I_{180}\right) /\left(I_{180}+I_{162}\right)\right]$, in which $I_{180}$ is the intensity of the precursor ion and $I_{162}$ is the intensity of its fragment. Kinetic IRMPD experiments have been carried out by irradiating the mass selected $\mathrm{m} / \mathrm{z} 180 \mathrm{u}$ precursor ion at four fixed wavelengths (namely: 3270, 3300, 3326 and $3345 \mathrm{~cm}^{-1}$ ). Each point of the kinetic curves represents a different irradiation time, within the 0-20 s range. The fingerprint region $\left(800-1900 \mathrm{~cm}^{-1}\right)$ has also been explored using the beamline of the free electron laser (FEL) at the Centre Laser Infrarouge d'Orsay (CLIO). ${ }^{23,24}$ The FEL beamline (electron energy set at $44 \mathrm{MeV}$ ) was coupled with a hybrid FT-ICR tandem mass spectrometer (APEX-Qe Bruker) equipped with a 7.0 T actively shielded magnet and a quadrupolehexapole interface for mass-filtering and ion accumulation, under control of the commercial software APEX 1.0. Mass-selection of the species under study was performed in the quadrupole and ions were accumulated in the hexapole containing argon buffer gas for $0.5 \mathrm{~s}$ for collisional cooling prior to their transfer into the ICR cell. The isolated ions were then irradiated for $220 \mathrm{~ms}$ through two attenuators to measure the entire fingerprint region spectrum without any saturation. A second IR FEL experiment was performed by fixing the irradiation time to $1 \mathrm{~s}$, with the aim of ascertaining the presence of the carbonyl absorption, characteristic of the open chain structure. After the FEL light irradiation the ions were mass-analyzed.

\subsection{NMR experiments}

D-Galactosamine. $\mathrm{HCl}$ (about $10 \mathrm{mg}$ ) was dissolved in $0.7 \mathrm{~mL}$ of deuterated methanol $\left(\mathrm{CD}_{3} \mathrm{OD}\right)$. The NMR spectra were recorded at $27{ }^{\circ} \mathrm{C}$ on a Bruker AVANCE 600 spectrometer operating at a proton frequency of $600.13 \mathrm{MHz}$ and equipped with a Bruker multinuclear z-gradient inverse probehead. The ${ }^{1} \mathrm{H}$ spectra were acquired by co-adding 64 transients with a recycle delay of $14.5 \mathrm{~s}$, using a $90^{\circ}$ pulse of $10 \mu$ s and $32 \mathrm{~K}$ data points. Data processing was carried out with Bruker TOPSPIN 3.5 software. An exponential function with $\mathrm{LB}=0.3 \mathrm{~Hz}$ was applied. The Free Induction Decay (FID) was Fourier transformed (FT) and all the spectra were manually phased and the polynomial baseline correction was applied. The $\alpha / \beta$ ratio was calculated by the integration of the anomeric $\alpha$ and $\beta$ proton signals and by normalizing the sum of the integrals to $100 \%$.

\subsection{Computational details}

The structures of the $\alpha$-GalN $\cdot \mathbf{H}^{+}$and $\beta$-GalN $\cdot \mathbf{H}^{+}$anomers (see Fig. 1) were optimized under gas-phase conditions using a 
Density Functional Theory-based ${ }^{25}$ approach in conjunction with the hybrid B3LYP functional, which is composed of the exchange functional of Becke and the correlation functional of Lee, Yang, and Parr. ${ }^{26}$ The 6-311++G(d,p) basis set was used for this purpose. ${ }^{27}$ Calculations were carried out employing the Gaussian-09 program (release E.01 ${ }^{28}$ ) for geometry optimizations and subsequent vibrational frequency estimations. The calculated harmonic frequencies have been corrected for the inherent vibrational anharmonicity, by applying the value 0.96 as the scaling factor. ${ }^{15}$ Conformational stability was further refined using the so-called extended block-localized wavefunction (BLW) method, ${ }^{29}$ which represents the simplest form of Valence Bond (VB) theory. ${ }^{30}$ Accordingly we investigated the most stable structures of both $\alpha$-GalN $\cdot \mathbf{H}^{+}$and $\beta$-GalN $\cdot \mathbf{H}^{+}$anomers and interpreted their conformational preferences. To this end, all geometries were re-optimized at the MP2/6-311++G(d,p) level and the emerging structures were used as input coordinates for BLW computations carried out using a stand-alone version of the Xiamen $\mathrm{VB}$ code $\left(\mathrm{XMVB},{ }^{31,32}\right)$ program. In line with Y. Mo's reference paper, ${ }^{18}$ we built the BLW of the primary Lewis structure where all electrons are actually localized on their respective functional groups (that is, all electron delocalization effects are deactivated from the input). In so doing, the energy difference between BLW and Hartree-Fock (HF) methods represents the magnitude of the electronic delocalization $\left(\Delta E_{\mathrm{del}}\right)$. More precisely, we decomposed the MP2/6-311++G(d,p) axial-equatorial energy difference $\left(\Delta E_{\alpha \rightarrow \beta}\right)$ into three components: electron delocalization $\left(\Delta E_{\mathrm{del}}\right)$ mainly given by both hyperconjugative and conjugative interactions, steric effects $\left[\Delta E_{\mathrm{s}}=\Delta E_{\alpha \rightarrow \beta}(\mathrm{BLW})\right]$ as a sum of Pauli exchange repulsion and electrostatic interactions and dispersion effects $\left[\Delta E_{\mathrm{disp}}=\Delta E_{\alpha \rightarrow \beta}-\left(\Delta E_{\mathrm{del}}+\Delta E_{\mathrm{s}}\right)\right] \cdot{ }^{18}$

\section{Results and discussion}

To ascertain any anomeric interconversion in the condensed phase, the starting $\left(t_{0 \mathrm{~h}}\right)$ methanol solution of D-galactosamine. $\mathrm{HCl}$ was subjected to ${ }^{1} \mathrm{H}-\mathrm{NMR}$ analysis and the same measurement was repeated after $24 \mathrm{~h}\left(t_{24 \mathrm{~h}}\right), 48 \mathrm{~h}\left(t_{48 \mathrm{~h}}\right)$, and finally after 12 days $\left(t_{12 \mathrm{~d}}\right.$; Fig. S2 in the ESI $\left.\dagger\right)$. The starting anomeric composition $(\alpha / \beta=3 / 97)$ was completely reversed after 12 days $(\alpha / \beta=72 / 28$; Table 1$)$, thus showing a clear prevalence of the $\alpha$ form once the anomeric equilibrium is attained in methanol.

It is worth noting that the galactosammonium ions $\mathrm{p} K_{\mathrm{a}}{ }^{33}$ (8.51 and 8.06 for $\alpha$ and $\beta$ anomer, respectively) allowed us to assume the concentration of neutral aminosugars as negligible, thus the signals detected in the ${ }^{1} \mathrm{H}-\mathrm{NMR}$ experiments are substantially due to protonated species. Furthermore, the anomeric

Table $1{ }^{1} \mathrm{H}$-NMR vs. ESI-IRMPD anomeric distribution measured for the same solution at different times

\begin{tabular}{lll}
\hline Solution age & ${ }^{1} \mathrm{H}-\mathrm{NMR} \alpha / \beta$ ratio & ESI-IRMPD $\alpha / \beta$ ratio \\
\hline$t_{0 \mathrm{~h}}$ & $3 / 97$ & $\sim 36 / 64$ \\
$t_{24 \mathrm{~h}}$ & $19 / 81$ & $\sim 75 / 25$ \\
$t_{48 \mathrm{~h}}$ & $32 / 68$ & $\sim 75 / 25$ \\
$t_{12 \mathrm{~d}}$ & $72 / 28$ & -
\end{tabular}

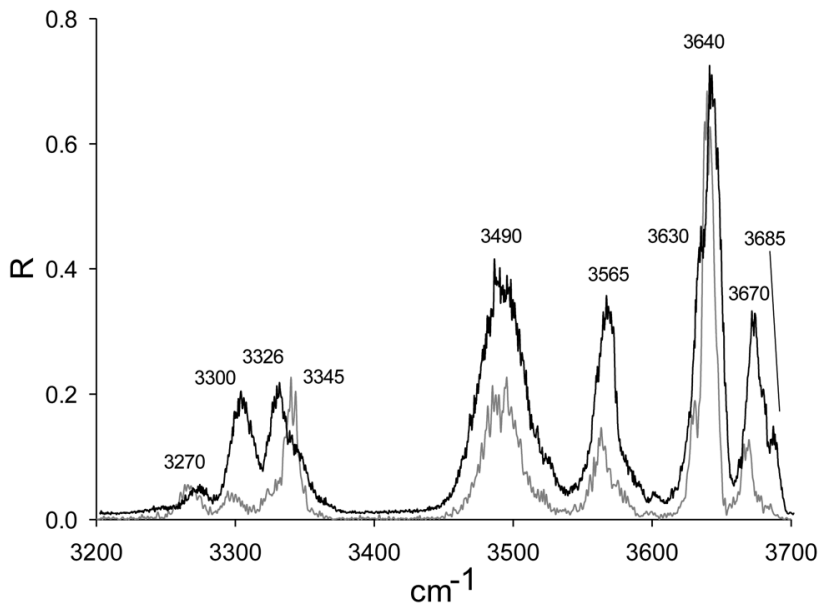

Fig. 2 IRMPD spectra of GalN. $\mathrm{H}^{+}$ions extracted from a $t_{\mathrm{oh}}$ (black line) and $t_{24 h}$ (grey line) methanol solution.

distribution of galactosammonium ions we found in methanol is basically different from the ${ }^{1} \mathrm{H}$-NMR data collected in water, where the $\beta$ anomer slightly prevails at the equilibrium. ${ }^{34}$ The same $t_{0 \mathrm{~h}}, t_{24 \mathrm{~h}}$ and $t_{48 \mathrm{~h}}$ epimerizing solutions were subjected to ESI-IRMPD analysis. The $t_{0 \mathrm{~h}}$ and $t_{24 \mathrm{~h}}$ spectra show significant differences in the intensities of four absorptions, namely at 3270 , 3300,3326 , and $3345 \mathrm{~cm}^{-1}$ (Fig. 2; the full 2800-3700 $\mathrm{cm}^{-1}$ spectrum of GalN $\cdot \mathbf{H}^{+}$ions isolated from the $t_{0 \mathrm{~h}}$ solution is reported in Fig. S3, ESI $\dagger$ ). Indeed, while the middle bands at 3300 and $3326 \mathrm{~cm}^{-1}$ predominate in the $t_{0 \mathrm{~h}}$ spectrum (black line in Fig. 2), the side bands ( 3270 and $3345 \mathrm{~cm}^{-1}$ ) become definitely more intense in the $t_{24 \mathrm{~h}}$ one (gray line in Fig. 2). Finally, the $t_{24 \mathrm{~h}}$ and $t_{48 \mathrm{~h}}$ spectra are virtually identical. This result clearly indicates these two pairs of bands as representative of different structures. As a matter of fact, since ESI-IRMPD is extremely sensitive to the conformational features of flexible ions, ${ }^{15}$ the occurrence of any modification in the spectral profiles of GalN $\cdot \mathbf{H}^{+}$ions differing only in the solution ages can be attributed to a different anomeric composition, or to a different conformational distribution of the gaseous mixture, or to both.

To get a closer look in these structural features, four IRMPD kinetics experiments have been performed on the $t_{0 \mathrm{~h}}, t_{24 \mathrm{~h}}$, and $t_{48 \mathrm{~h}}$ solutions (Fig. S4, S5, ESI $\dagger$, and Fig. 3 respectively) by fixing the irradiating wavelength at 3270, 3300, 3326, and $3345 \mathrm{~cm}^{-1}$, respectively. The kinetic approach, proposed by E. R. Williams and coworkers, ${ }^{35}$ assesses the composition of a mixture of co-existing isomers by taking advantage of the different frequency of the relevant absorptions using IRMPD experiments. ${ }^{36}$ Increasing the irradiation time at a fixed resonant wavelength, the precursor ion signal asymptotically decreases to zero or reaches a plateau. The latter case indicates that at least two spectroscopically distinguishable species are present and that they do not interconvert in the gas phase during the kinetic experiment. Furthermore, the position of the plateau in the precursor ion curve directly provides the percentage abundance of the off-resonance precursor ion. Our kinetic experiments invariably indicate the achievement of a plateau (Fig. 3). In particular, the profiles of the kinetics measured on the middle 


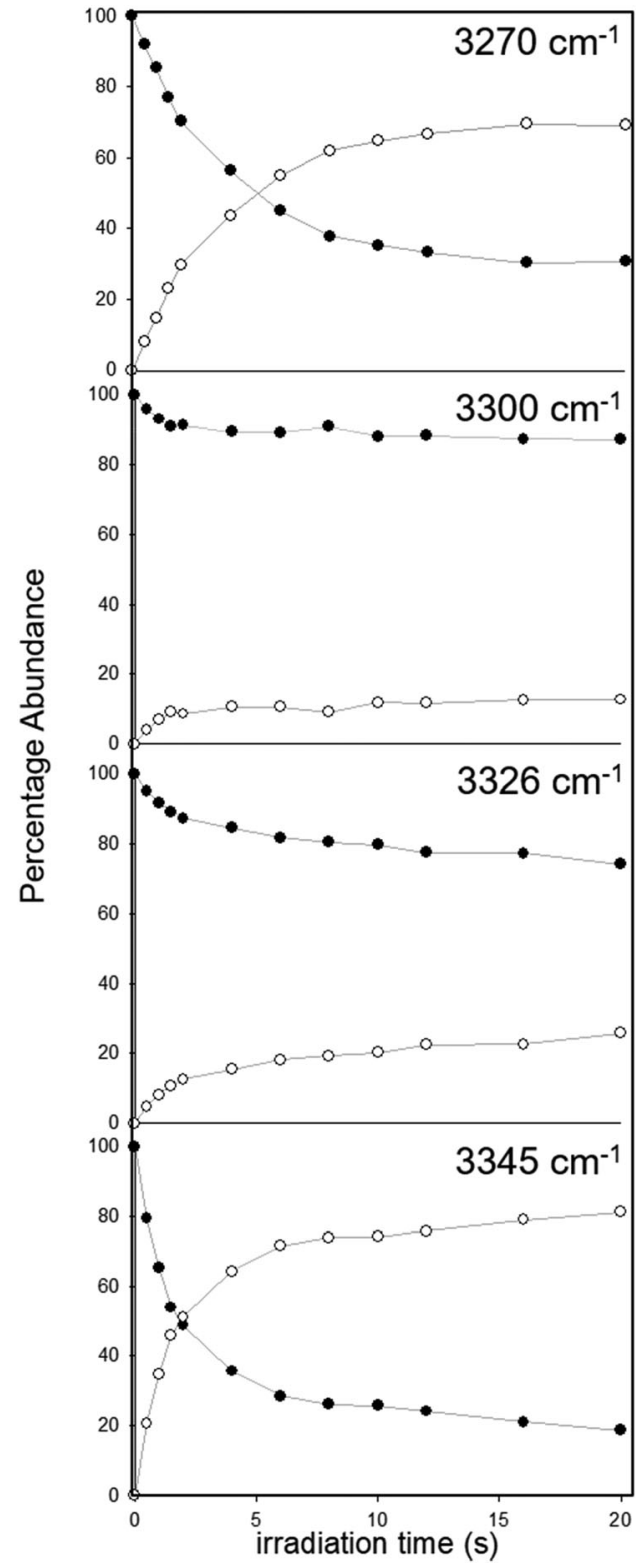

Fig. 3 Percentage abundancies of the precursor ion GalN. $\mathbf{H}^{+}$(full circles) and the relevant dehydrated fragment ion (empty circles) as a function of the irradiation time measured on the $t_{48 \mathrm{~h}} \mathrm{GalN} \cdot \mathbf{H C l}$ solution at 3270,3300 , 3326 , and $3345 \mathrm{~cm}^{-1}$. bands (3300 and $3326 \mathrm{~cm}^{-1}$, Fig. 3) are similar, as well as the curves arising from the measurements carried out on the side bands (3270 and $3345 \mathrm{~cm}^{-1}$, Fig. 3). This evidence nicely agrees with our previous statement that the 3300 and $3326 \mathrm{~cm}^{-1}$ bands can be attributed to the same species, which approximately represents $25 \%$ of the $t_{24 \mathrm{~h}}$ and $t_{48 \mathrm{~h}}$ mixtures, while the remaining percentage corresponds to isomers on-resonance at 3270 and $3345 \mathrm{~cm}^{-1}$.

In the current context, it should also be remarked that the combination of the plateau values of the $t_{24 \mathrm{~h}}$ and $t_{48 \mathrm{~h}}$ solutions does not correspond to $100 \%$ (90\% and 95\%, respectively), due to an incomplete overlapping between the ion cloud and the laser beam. ${ }^{35}$ The combination of the latter effect with a second one, i.e. the presence of transient species characterized by different absorptions, might explain the lower sum of the plateau values observed in the $t_{0 \mathrm{~h}}$ solution (about $75 \%$ ). In order to assign the experimental IR absorptions, the theoretical frequencies have been calculated at the B3LYP/6-311++G(d,p) level of theory for several conformers of both $\alpha$-GalN $\cdot \mathbf{H}^{+}$and $\beta$-GalN $\cdot \mathbf{H}^{+}$anomers, whose structures were previously optimized at the same level of theory (Table 2). In this respect, the analyzed structures have been selected on the basis of the following considerations: (a) open chain species have not been investigated at all since the fingerprint region (800-1900 $\mathrm{cm}^{-1}$ ) ESI-IRMPD-MS experiments, carried out on both the $t_{0 \mathrm{~h}}$ and $t_{24 \mathrm{~h}}$ solutions, did not point out any appreciable absorption of the relevant carbonyl, typically falling in the $1650-1750 \mathrm{~cm}^{-1}$ range (Fig. S6 in the ESI $\dagger$ ); (b) the significant energy gap existing between the ${ }^{1} \mathrm{C}_{4}$ and the ${ }^{4} \mathrm{C}_{1}$ chairs (Table 2) allowed us to avoid the optimization of some conformers, particularly in the $\beta$ anomer series. In Table 2 the notation "cc" or "cl" has been indicated for all the conformations (A1-2, A4, B1-2, B4) in which the geometric parameters allow the "locking" of the $\mathrm{O} 3 \mathrm{H}-\mathrm{O} 4 \mathrm{H}-\mathrm{O} 6 \mathrm{H}$ hydrogen bonding network.

The lowest energy conformer of the $\alpha$ anomer (A1) is about $2.5 \mathrm{kcal} \mathrm{mol}^{-1}$ more stable than the most stable structure of the $\beta$ anomer (B1). After a careful analysis of the calculated spectra (Table 2 and Fig. S7-S23 in the ESI $\dagger$ ) several considerations concerning the $\mathrm{N}-\mathrm{H}$ stretching region, which invariably includes three absorptions bands ( $\nu 1, \nu 2$, and $\nu 3$ in Table 2$)$, can be made. Since absorptions in the $3180-3245 \mathrm{~cm}^{-1}$ range appear weak and broad (Fig. 2), they were not considered for conformational diagnostic purposes, thus excluding the calculated $\nu 1$ frequency

Table 2 Free energies $\left(\mathrm{kcal} \mathrm{mol}^{-1}\right)$ and spectral features $\left(\mathrm{cm}^{-1}\right)$ of the $\alpha$ and $\beta$ anomers of the protonated galactosamine in vacuo calculated at the B3LYP/6-311G++(d,p) level of theory

\begin{tabular}{|c|c|c|c|c|c|c|c|c|c|c|c|c|c|}
\hline$\alpha$-GalN. $\mathbf{H}^{+}$ & Conf. & Chair & $\nu 1$ & $\nu 2$ & $\nu 3$ & $\Delta G$ & $\beta$-GalN. $\mathbf{H}^{+}$ & Conf. & Chair & $\nu 1$ & $\nu 2$ & $\nu 3$ & $\Delta G$ \\
\hline A1 & $\mathrm{G}-t / \mathrm{cl}$ & ${ }^{4} \mathrm{C}_{1}$ & 3199 & 3274 & 3345 & 0.00 & B1 & $\mathrm{G}-t / \mathrm{cl}$ & ${ }^{4} \mathrm{C}_{1}$ & 3223 & 3308 & 3338 & 2.53 \\
\hline A2 & $\mathrm{G}-g+/ \mathrm{cl}$ & ${ }^{4} \mathrm{C}_{1}$ & 3198 & 3274 & 3344 & 0.16 & B2 & $\mathrm{G}-g+/ \mathrm{cl}$ & ${ }^{4} \mathrm{C}_{1}$ & 3221 & 3307 & 3338 & 2.65 \\
\hline A3 & $\mathrm{G}+g-$ & ${ }^{4} C_{1}$ & 3197 & 3264 & 3343 & 3.80 & B3 & $\mathrm{G}+g-$ & ${ }^{4} \mathrm{C}_{1}$ & 3227 & 3307 & 3335 & 6.18 \\
\hline A4 & $\mathrm{G}-g-/ \mathrm{cc}$ & ${ }^{4} C_{1}$ & 3213 & 3278 & 3340 & 7.52 & B4 & $\mathrm{G}-g-/ \mathrm{cc}$ & ${ }^{4} \mathrm{C}_{1}$ & 3242 & 3319 & 3329 & 10.01 \\
\hline A5 & $\mathrm{G}-g-$ & ${ }^{4} C_{1}$ & 3202 & 3269 & 3342 & 7.93 & B5 & $\mathrm{G}-t$ & ${ }^{4} \mathrm{C}_{1}$ & 3241 & 3318 & 3331 & 11.88 \\
\hline A6 & $\mathrm{G}-t$ & ${ }^{4} C_{1}$ & 3212 & 3278 & 3343 & 9.40 & B6 & $\mathrm{G}+t$ & ${ }^{1} \mathrm{C}_{4}$ & 3235 & 3316 & 3344 & 20.97 \\
\hline A7 & $\mathrm{G}-t$ & ${ }^{4} \mathrm{C}_{1}$ & 3213 & 3279 & 3344 & 9.68 & B7 & $\mathrm{G}-g+$ & ${ }^{1} \mathrm{C}_{4}$ & 3245 & 3319 & 3335 & 21.82 \\
\hline A8 & $\mathrm{G}-t$ & ${ }^{1} \mathrm{C}_{4}$ & 3240 & 3306 & 3361 & 11.07 & & & & & & & \\
\hline A9 & $\mathrm{G}+t$ & ${ }^{1} \mathrm{C}_{4}$ & 3236 & 3293 & 3360 & 11.82 & & & & & & & \\
\hline A10 & $\mathrm{G}-g-$ & ${ }^{1} \mathrm{C}_{4}$ & 3231 & 3294 & 3362 & 12.42 & & & & & & & \\
\hline
\end{tabular}


(Table 2) from the analysis. The 3270 and $3345 \mathrm{~cm}^{-1}$ bands can be safely attributed to the ${ }^{4} \mathrm{C}_{1}-\alpha$ anomers, while the 3300 and $3326 \mathrm{~cm}^{-1}$ pair matches the $\mathrm{N}-\mathrm{H}$ region of the $\beta$ anomers (Table 2). Particularly, six structures fit the experimental data, namely A1, A2, and A3 for the $\alpha$ anomer, and B1, B2, and B3 for the $\beta$ one (see Fig. S7-S9 and S17-S19 respectively in the ESI $\dagger$ ). Moreover, at the B3LYP/6-311++G(d,p) level of theory the $86^{\circ}$ rotation of the C5-C6-O6-H6 dihedral angle (A1 $\rightarrow$ A2), as well as the $141^{\circ}$ rotation of the O5-C5-C6-O6 $(\mathbf{A 1} \rightarrow \mathbf{A 3})$ dihedral angle increase the free energy by 0.16 and $3.80 \mathrm{kcal} \mathrm{mol}^{-1}$, respectively (Table 2). The IR calculated spectra of $\mathbf{A 1}$ and $\mathbf{A 2}$ conformers are substantially superimposable, while since in the A3 conformer the $\mathrm{O} 4-\mathrm{H} \cdots \mathrm{O} 6-\mathrm{H}$ interaction is lost, the $\mathrm{O} 4-\mathrm{H}$ stretching is predicted to be blue shifted by $166 \mathrm{~cm}^{-1}$ with respect to the same absorption in the A1-2 structures. Concerning the $\beta$ anomer, the $88^{\circ}$ rotation of the $\mathrm{C} 5-\mathrm{C} 6-\mathrm{O} 6-\mathrm{H} 6(\mathbf{B 1} \rightarrow \mathrm{B} 2)$ dihedral angle does not modify neither the free energy value nor the vibrational spectrum. On the other hand, the $140^{\circ}$ rotation of the O5-C5-C6-O6 (B1 $\rightarrow$ B3) dihedral angle increases the free energy by $3.53 \mathrm{kcal} \mathrm{mol}^{-1}$ yielding a $173 \mathrm{~cm}^{-1}$ blue shift of the calculated $\mathrm{O} 4-\mathrm{H}$ stretching mode. Unfortunately, the O4-H stretching predicted in the A3 and B3 IR spectra is not diagnosable, since such a signal is predicted in the "crowded" free $\mathrm{O}-\mathrm{H}$ stretching region (3600-3700 $\left.\mathrm{cm}^{-1}\right)$. Furthermore, it is interesting to observe that the lower energy structures are characterized by a clockwise (cl) arrangement of the $\mathrm{O} 3 \mathrm{H}-\mathrm{O} 4 \mathrm{H}-\mathrm{O} 6 \mathrm{H}$ hydrogen bond chain (Table 2). An inversion of this chain orientation makes the matching between the calculated spectra and the experimental one definitely worse. Therefore such a spectroscopic comparison points to the coexistence of conformers A1-3 and B1-3, even if the free energy of both A3 and B3 (3.80 and $6.18 \mathrm{kcal} \mathrm{mol}^{-1}$ respectively) is high enough to assume their relative concentrations as fairly negligible (see Fig. 4).

Once assessed the identity of the species populating the gasphase mixture, the actual ESI-IRMPD vs. ${ }^{1} \mathrm{H}-\mathrm{NMR}$ anomeric distributions can be discussed (Table 1). Provided that any gasphase anomerization is ruled out by the occurrence of a plateau in the IRMPD kinetics (Fig. 3), the equilibrium anomeric distribution observed in the $t_{12 \mathrm{~d}}{ }^{1} \mathrm{H}-\mathrm{NMR}$ measurement basically converges to the distribution observed in both the $t_{24 \mathrm{~h}}$ and $t_{48 \mathrm{~h}}$ ESI-IRMPD experiments, by favoring the $\alpha$ anomer by about three times. Nevertheless, the anomerization timescale observed in the ESI process is remarkably shorter. Indeed, when the $t_{0 \mathrm{~h}}$ solution, predominantly containing the $\beta$ anomer $(\alpha / \beta=3 / 97$ Table 1), undergoes the ESI process, the $\alpha$ fraction increases up to $37 \%$; moreover, the distribution arising from the ESI source achieves the $\alpha / \beta=75 / 25$ ratio after $24 \mathrm{~h}$, and substantially does not undergo any further change in the next 24 hours $\left(t_{48 \mathrm{~h}}\right)$, while the anomeric distribution in methanol still favors the $\beta$ anomer $\left(\alpha / \beta=32 / 68\right.$ in the $t_{48 \mathrm{~h}}$ solution), and reaches the $\alpha / \beta=72 / 28$ ratio only after a longer time. Although difficult to predict, the ESI-IRMPD experiments unequivocally show that the anomeric interconversion is achieved in a remarkably shorter timescale range. This effect points to the presence of a relatively efficient catalytic process occurring in the electrospray source where the nano-droplet environment is characterized by a lower $\mathrm{pH}$ value

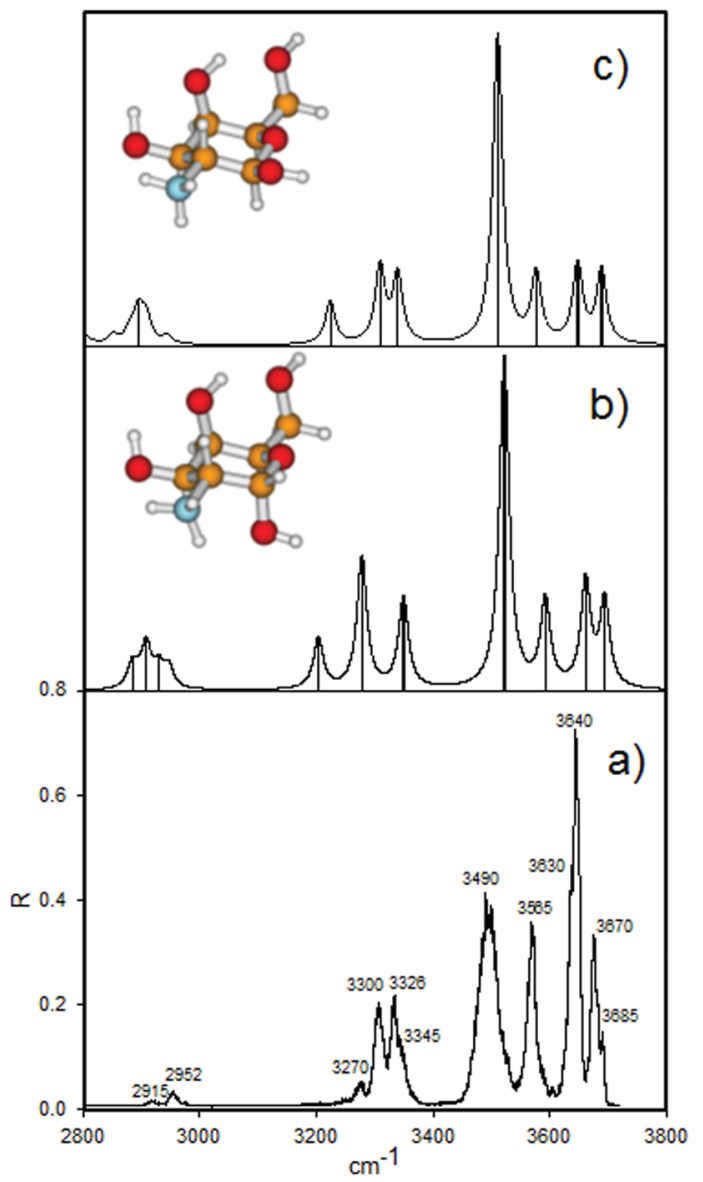

Fig. 4 (a) IRMPD spectrum of GalN. $\mathrm{H}^{+}$ions as extracted from $t_{0 \mathrm{~h}}$ methanol solution compared with the calculated IR spectra of A1 (b) and B1 (c) optimized structures at the B3LYP/6-311G++(d,p) level of theory.

and higher ionic strength and is converted to a confined-volume reactor. ${ }^{37}$ In this regard, the authors would like to underline that currently the coupling of the ESI source with different tandem MS techniques (i.e., collision induced dissociation, spectroscopic approaches) is widely used to characterize ionized biological molecules in the gas-phase. Nevertheless, the electrospray can induce a catalytic effect on the solution processes or transmit to the gas-phase species unstable in solution. ${ }^{38,39}$ Actually, the gas-phase is the only environment where the intimate nature of intra- and intermolecular interactions can be isolated and studied, but the gas-phase picture does not necessarily mirror the solution one from which it arises and any comparison needs the application of different experimental approaches suitable for investigating these environments.

Finally, we applied the BLW method ${ }^{18}$ on the most representative A1-2 and B1-2 structures, to dissect the contributions playing a role in the differential anomeric stabilization. This approach assesses the individual contributions arising from steric $\left(\Delta E_{\mathrm{s}}\right)$, delocalization $\left(\Delta E_{\text {del }}\right)$, and dispersion $\left(\Delta E_{\text {disp }}\right)$ terms, through the application of the Valence Bond Theory. It stimulated an interesting debate about the anomerization equilibrium of several neutral tetrahydropyran ${ }^{18}$ and tetrahydrothiopyran ${ }^{40}$ derivatives but, to the best of our knowledge, so far it has never 
Table 3 Energy differences $\left(\Delta E_{\alpha \rightarrow \beta}\right)$ calculated for the $\mathbf{A} 1 \rightarrow \mathbf{B} 1$ and A2 $\rightarrow$ B2 transitions with decomposed contributions from steric, electronic delocalization, and dispersion effects

\begin{tabular}{lllll}
\hline & $\Delta E \mathrm{MP}^{a}$ & $\Delta E_{\mathrm{s}}{ }^{b}$ & $\Delta E_{\text {del }}{ }^{c}$ & $\Delta E_{\text {disp }}{ }^{d}$ \\
\hline$\Delta E_{\mathbf{A} 1 \rightarrow \mathbf{B} 1}$ & 4.02 & 4.34 & -1.46 & 1.15 \\
$\Delta E_{\mathbf{A} 2 \rightarrow \mathbf{B} 2}$ & 3.76 & 4.14 & -1.42 & 1.04
\end{tabular}

${ }^{a} \Delta E_{\alpha \rightarrow \beta}$ calculated for the $\mathbf{A 1} \rightarrow \mathbf{B} 1$ and $\mathbf{A} 2 \rightarrow \mathbf{B} 2$ transitions ${ }^{b}$ with decomposed contributions from steric, ${ }^{c}$ electronic delocalization, ${ }^{d}$ and dispersion effects (values in $\mathrm{kcal} \mathrm{mol}^{-1}$ ).

been applied to charged species. The MP2 $\Delta E_{\alpha \rightarrow \beta}$ for the $\mathbf{A 1} \rightarrow \mathbf{B 1}$ and A2 $\rightarrow$ B2 transitions, with the relevant energetic contributions are reported in Table 3.

The computational data indicate that the anomeric equilibrium of protonated galactosamine is basically driven by steric factors (as a sum of Pauli exchange repulsion and electrostatic interactions) rather than electronic (conjugative ${ }^{41}$ and hyperconjugative) delocalization effects. In this respect, it should be remarked that this result is in qualitative and quantitative agreement with the MP2 and BLW-based data previously obtained for energy differences between $\alpha$ and $\beta$ anomers of substituted tetrahydropyran $\mathrm{C}_{5} \mathrm{OH}_{9} \mathrm{Y}(\mathrm{Y}=\mathrm{F}, \mathrm{Cl}, \mathrm{OH}, \mathrm{NH} 2$, and $\mathrm{CH} 3) .{ }^{18}$ Such a comparison suggests a scarce influence of the charge state of the anomeric system investigated in the BLW analysis, a hypothesis whose confirmation needs further investigations. We would like to further underline that the data as emerged from BLW decomposition are not inconsistent with the hyperconjugative explanation of the anomeric effect. More specifically, Table 3 shows that $\alpha$ anomers are stabilized by steric (4.34, and $4.14 \mathrm{kcal} \mathrm{mol}^{-1}$ ) and dispersion $(1.15$, and $\left.1.04 \mathrm{kcal} \mathrm{mol}^{-1}\right)$ interactions, whereas $\beta$ anomers are stabilized by delocalization $\left(-1.46\right.$ and $\left.-1.42 \mathrm{kcal} \mathrm{mol}^{-1}\right)$ effects. As a result, at the MP2/6-311++G(d,p) level of theory, the anomeric energy difference for $\mathbf{A 1} \rightarrow \mathbf{B 1}$ and $\mathbf{A} 2 \rightarrow \mathbf{B} 2$ transitions is 4.02 and $3.76 \mathrm{kcal} \mathrm{mol}^{-1}$, respectively. This trend is ascribed to the fact that the hyperconjugative $\left(\mathrm{n}_{\mathrm{O}} \rightarrow \sigma_{\mathrm{C}(\mathrm{OH})^{*}}\right)$ and conjugative interactions cannot be separated effectively when comparing BLW-localized to HF-delocalized electronic wavefunctions (see Computational details).

\section{Conclusions}

The IRMPD investigation of a solution containing a mixture of D-galactosamine. $\mathrm{HCl}$ unprotected anomers unveiled their structural features in the gas phase. Despite the experimental difficulties, namely the solution instability of the starting epimeric distribution and the overlapping of a number of IRMPD signals, some characteristic IR absorptions of both the anomers of protonated galactosamine have been assigned. According to B3LYP/6-311G++(d,p) calculations, the most stable $\alpha$ and $\beta$ epimers basically exist in two conformations $(\mathrm{G}-t / \mathrm{cl}$ and $\mathrm{G}-g+/ \mathrm{cl}$ ), characterized by a ${ }^{4} \mathrm{C}_{1}$ chair and a clockwise arrangement of the $\mathrm{O} 3 \mathrm{H}-\mathrm{O} 4 \mathrm{H}-\mathrm{O} 6 \mathrm{H}$ hydrogen bond network. The $\alpha / \beta$ anomeric distribution measured in the condensed phase using ${ }^{1} \mathrm{H}-\mathrm{NMR}$ has been compared with that measured in the gas phase using
ESI-IRMPD-MS of the same solution. Such a comparison, extended to increasing aged solutions, points out a catalytic effect of the ESI process, where the anomeric interconversion is achieved on a significantly shorter timescale. Additionally, according to the BLW analysis of protonated galactosamine in the gas-phase, the steric energy term (which consists of both electrostatic interactions -stabilizing and not - and Pauli repulsion) plays a key role in modulating the anomeric preference of the $\alpha$ form.

\section{Conflicts of interest}

There are conflicts to declare.

\section{Acknowledgements}

Financial support by the Ministero dell'Istruzione dell'Università e della Ricerca is gratefully acknowledged. CLIO's staff in Orsay, Maurizio Speranza, Maria Elisa Crestoni, and Annito Di Marzio in Rome are gratefully acknowledged for their support. The authors acknowledge Prof. Ruggero Caminiti for providing free computing facilities on NARTEN Cluster HPC Facility and the RCMD at the CTF Department of "Sapienza" for sharing computational resources.

\section{Notes and references}

1 J. J. Distler and S. Roseman, J. Biol. Chem., 1960, 235, 2538.

2 W. Peng, l. Zou, S. Bhamidi, M. R. McNeil and T. L. Lowary, J. Am. Chem. Soc., 2012, 77, 9826.

3 J. M. Silla, R. A. Cormanich, R. Rittner and M. P. Freitas, Carbohydr. Res., 2014, 396, 9.

4 E. J. Cocinero and P. Çarçabal, Top. Curr. Chem., 2015, 364, 299.

5 I. Pena, L. Kolesnikova, C. Cabezas, C. Bermudez, M. Berdakin, A. Simao and J. L. Alonso, Phys. Chem. Chem. Phys., 2014, 16, 23244.

6 I. Pena, C. Cabezas and J. L. Alonso, Chem. Commun., 2015, 51, 10115.

7 P. Écija, I. Uriarte, L. Spada, B. G. Davis, W. Caminati, F. J. Basterretxea, A. Lesarri and E. J. Cocinero, Chem. Commun., 2016, 52, 6241.

8 J. P. Simons, R. A. Jockusch, P. Çarçabal, I. Hünug, R. T. Kroemer, N. A. Macleod and L. C. Snoek, Int. Rev. Phys. Chem., 2005, 3-4, 489.

9 C. S. Contreras, N. C. Polfer, J. Oomens, J. D. Steill, B. Bendiak and J. R. Eyler, Int. J. Mass Spectrom., 2012, 330-332, 285.

10 A. Filippi, C. Fraschetti, F. Rondino, S. Piccirillo, V. Steinmetz, L. Guidoni and M. Speranza, Int. J. Mass Spectrom., 2013, 354-355, 54.

11 C. Fraschetti, A. Filippi, S. Borocci, V. Steinmetz and M. Speranza, ChemPlusChem, 2014, 79, 1.

12 C. Fraschetti, A. Filippi, L. Mannina, A. P. Sobolev and M. Speranza, J. Mass Spectrom., 2014, 49, 608. 
13 R. A. Coates, C. P. McNary, G. C. Boles, G. Berden, J. Oomens and P. B. Armentrout, Phys. Chem. Chem. Phys., 2015, 17, 25799.

14 Y. Tan and N. C. Polfer, J. Am. Soc. Mass Spectrom., 2015, 26(2), 359.

15 C. Fraschetti, A. Filippi, L. Guarcini, V. Steinmetz and M. Speranza, J. Phys. Chem. B, 2015, 119(20), 6198.

16 V. Lepere, K. Le Barbu-Debus, C. Clavaguera, D. Scuderi, G. Piani, A. L. Simon, F. Chirot, L. Macaleese, P. Dugourd and A. Zehnacker, Phys. Chem. Chem. Phys., 2016, 18(3), 1807.

17 D. Corinti, L. Mannina, B. Chiavarino, V. Steinmetz, S. Fornarini and M. E. Crestoni, Chem. Phys. Lett., 2016, 646, 162.

18 Y. Mo, Nat. Chem., 2010, 2, 666.

19 G. F. Bauerfeldt, T. M. Cardozo, M. S. Pereira and C. O. da Silva, Org. Biomol. Chem., 2013, 11, 299.

20 M. P. Freitas, Org. Biomol. Chem., 2013, 11, 2885.

21 N. Hasanzadeh, D. Nori-Shargh, M. Farzipour and B. Ahmadi, Org. Biomol. Chem., 2015, 13, 6965.

22 P. G. Rodriguez Ortega, M. Montejo and J. J. Lopez Gonzalez, ChemPhysChem, 2016, 17, 530.

23 J. Lemaire, P. Boissel, M. Heninger, G. Mauclaire, G. Bellec, H. Mestdagh, A. Simon, S. Le Caer, J. M. Ortega, F. Glotin and P. Maitre, Phys. Rev. Lett., 2002, 89, 273002.

24 J. M. Bakker, T. Besson, J. Lemaire, D. Scuderi and P. Maitre, J. Phys. Chem. A, 2007, 111(51), 13415.

25 R. G. Parr and W. Yang, Density-Functional Theory of Atoms and Molecules, Oxford University Press, New York, 1989.

26 A. D. Becke, J. Chem. Phys., 1993, 98, 5648; C. Lee, W. Yang and R. G. Parr, Phys. Rev. B: Condens. Matter Mater. Phys., 1988, 37, 785.

27 W. J. Hehre, L. v. R. Radom, P. Schleyer and J. A. Pople, Ab Initio Molecular Orbital Theory, Wiley, New York, 1986.

28 M. J. Frisch, G. W. Trucks, H. B. Schlegel, G. E. Scuseria, M. A. Robb, J. R. Cheeseman, G. Scalmani, V. Barone, B. Mennucci, G. A. Petersson, H. Nakatsuji, M. Caricato, X. Li, H. P. Hratchian, A. F. Izmaylov, J. Bloino, G. Zheng, J. L. Sonnenberg, M. Hada, M. Ehara, K. Toyota, R. Fukuda, J. Hasegawa, M. Ishida, T. Nakajima, Y. Honda, O. Kitao, H. Nakai, T. Vreven, J. A. Montgomery Jr, J. E. Peralta,
F. Ogliaro, M. Bearpark, J. J. Heyd, E. Brothers, K. N. Kudin, V. N. Staroverov, R. Kobayashi, J. Normand, K. Raghavachari, A. Rendell, J. C. Burant, S. S. Iyengar, J. Tomasi, M. Cossi, N. Rega, J. M. Millam, M. Klene, J. E. Knox, J. B. Cross, V. Bakken, C. Adamo, J. Jaramillo, R. Gomperts, R. E. Stratmann, O. Yazyev, A. J. Austin, R. Cammi, C. Pomelli, J. W. Ochterski, R. L. Martin, K. Morokuma, V. G. Zakrzewski, G. A. Voth, P. Salvador, J. J. Dannenberg, S. Dapprich, A. D. Daniels, Ö. Farkas, J. B. Foresman, J. V. Ortiz, J. Cioslowski and D. J. Fox, Gaussian 09, Revision E.01, Gaussian, Inc., Wallingford CT, 2009.

29 Y. Mo, L. Song and Y. Lin, J. Phys. Chem. A, 2007, 111, 8291.

30 S. Sason and P. C. Hiberty, A Chemist's Guide to Valence Bond Theory, Wiley-Interscience, New Jersey, 2008.

31 Z. Chen, F. Ying, X. Chen, J. Song, P. Su, L. Song, Y. Mo, Q. Zhang and W. Wu, Int. J. Quantum Chem., 2015, 115, 737. 32 L. Song, Y. Mo, Q. Zhang and W. Wu, J. Comput. Chem., Jpn., 2005, 26, 514.

33 A. Blasko, C. A. Bunton, S. Bunel, C. Ibarra and E. Moraga, Carbohydr. Res., 1997, 298, 163.

34 D. Horton, J. S. Jewell and K. D. Philips, J. Org. Chem., 1966, 31(12), 4022.

35 J. S. Prell, T. M. Chang, J. A. Biles, G. Berden, J. Oomens and E. R. Williams, J. Phys. Chem. A, 2011, 115, 2745.

36 D. Corinti, A. De Petris, C. Coletti, N. Re, B. Chiavarino, M. E. Crestoni and S. Fornarini, ChemPhysChem, 2017, 18(3), 318.

37 X. Yan, R. M. Bain and R. G. Cooks, Angew. Chem., Int. Ed., 2016, 55, 12960.

38 C. Fraschetti, M. Aschi, A. Filippi, A. Giardini and M. Speranza, Chem. Commun., 2008, 2544.

39 M. Aschi, C. Fraschetti, A. Filippi and M. Speranza, J. Mass Spectrom., 2009, 44, 1038.

40 C. Wang, F. Ying, W. Wu and Y. Mo, J. Org. Chem., 2014, 79, 1571.

41 Conjugative electronic delocalization effects (often termed in the literature as geminal rearrangements) are expected to involve molecular orbitals sharing common apex atoms with either the substituent $(\mathrm{OH})$ or the anomeric oxygen atom. 